\title{
Interference in the Acquisition of the Present Perfect Continuous: Implica- tions of a Grammaticality Judgment Test
}

\author{
Jason Miin-Hwa Lim* \\ Centre for the Promotion of Knowledge and Language Learning, Malaysian University of Sabah, Locked Bag 2073, \\ Teluk Sepanggar, 88999 Kota Kinabalu, Malaysia
}

\begin{abstract}
Linguistic interference in the acquisition of tenses has remained a fertile area for extensive studies on the teaching of English to speakers of other languages. Congruent with previous studies, this study aims to find out whether errors in the learning of a grammatical category is more ascribable to negative transfer resulting from learners' first language or the rules governing its use in the target language. Employing a grammaticality judgment test in the form of an elicitation procedure, the researcher focuses on second language learners' acquisition of the present perfect continuous in an attempt to investigate the extent to which interference may occur as a result of learners' confusion with temporal and aspectual values that collectively form part of the learners' mother tongue and second language. Using the data elicited, the researcher has found that linguistic interference should not be construed as merely negative transfer from the learner's first language because temporal and aspectual values associated with verb forms in the target language itself may also be an essential component of interference. Based on the findings, the researcher has recommended a three-pronged interactive approach to the teaching of the present perfect continuous, related verbal categories, and temporal/frequency adverbials.
\end{abstract}

Keywords: Second language acquisition, English tenses, linguistic interference, teaching material.

\section{INTRODUCTION}

Interference has long been regarded as one of the major factors causing difficulties in the acquisition of a second language, yet what actually constitutes interference remains a subject of great interest. This may be partly ascribed to the fact that the term 'interference' has been assigned different definitions by linguists and researchers. Interference has been specifically defined as 'negative transfer' [1] or the influence that knowledge of one language has on the way a bilingual speaks or writes in another language [2,3]. Alternatively, it may also refer generally to "a cause of errors by someone learning a new language" (p. 182) [4]. In this study, 'interference' is basically linguistic in nature, and it does not cover other factors, particularly non-linguistic causes. The aforementioned semantic scopes of interference need to be discussed in order to arrive at a working definition for this paper. First, linguistic interference may not always emanate from a learner's first language, given that it may also occur as a result of a learner's target language [5-8]. This has led us to a discussion on the distinction between interlingual and intralingual interference. On the one hand, right back in the 1970s, interlingual interference was defined as "the systematic influence of the native language in the learner's attempts to use (produce and perceive) the target language" (p. 52) [9], and it occurs when the learner negatively transfers the knowledge of his first language (L1) in the learning of the target language (TL). Errors which occur as a result of it are regarded as interlingual errors [10].

*Address correspondence to this author at the Centre for the Promotion of Knowledge and Language Learning, Malaysian University of Sabah, Locked Bag 2073, Teluk Sepanggar, 88999 Kota Kinabalu, Malaysia; Tel: 6088-320000 ext. 5026 or 6016-8298305; Fax: 6088-435708; E-mail: drjasonlim@gmail.com
On the other hand, the term 'intralingual interference', which has thus far been used less frequently, refers to "interference from other forms of the target language" (p. 231) [11]. It has been considered significant in causing errors in second language learning by some researchers [e.g., 5, 8, 11]. Duskova [11], in particular, claims that "a large number of errors seem to have little, if any, connection with the mother tongue" (p. 222). He considered these errors as being basically morphological in nature. Among the errors pertaining to verbs are those related to subject-verb agreement, confusion of the bare infinitive (base form) and the past participle, confusion of the present participle and the past participle, errors in the forms of irregular verbs, and difficulty in distinguishing the active voice from the passive voice. Similarly, Richards [8] defines intralingual errors as those which occur as a result of interference from the application of general learning strategies similar to those manifested in first language acquisition. This means that intralingual errors are committed as some rules or features are transferred from the target language itself to another situation requiring application of other rules or features within the same language.

More specifically, intralingual errors have been viewed as those that reflect the learner's competence at a particular stage, and they are evidence of some general characteristics of first language acquisition [8]. They have been found to be non-interlingual in nature as they are not directly caused by the differences between their first language and second language. Cognitively speaking, what is arguable here is the extent to which these errors are not 'directly caused' by interlingual differences. In other words, it would be interesting to discuss the degree to which interlingual distinctions and intralingual differences may operate simultaneously to result in interference. Such a focus also explains why a working definition adopted by the researcher for interference in this 
study should be 'structures or features in either the first or target language, which may have negative influence over the learning of the target language'.

Numerous recent studies [e.g., 12-15] have shown that interlingual interference does occur in the process of writing in English as a second/foreign language. More interestingly, in the writing process, past studies involving error analyses of English compositions [e.g., 15-17] have also indicated that verb forms stand out as a major linguistic category involving a large number of competence errors committed by second language learners. However, despite previous researchers' knowledge of the significant proportion of errors related to verb forms as compared to other competence errors, teachers may not always be able to use the related findings to help learners overcome the linguistic interference involved in second language learning of the verbs, particularly if an in-depth study is not conducted to find out the ways in which learners are confused over different verb forms in various situations. This means that even though error analysis of written compositions may give us ideas of the proportions of different categories of errors, we need to come up with an elicitation procedure (e.g., a procedure involving a grammaticality judgment test which will be explained in the ensuing section) that can thoroughly investigate the possible ways in which learners' errors are ascribable to such linguistic interference. A detailed elicitation procedure that focuses on a particular verbal category is essential in that it may enlighten us on how specific teaching and learning strategies can be introduced to offset such interference in the internalization of English verb forms. A thorough study of ungrammatical linguistic forms may have interesting pedagogical significance in that the findings yielded in the analysis may show teachers ways of highlighting essential differences between (i) the time frames and aspects indicated by verb forms in the target language, and (ii) those perceived by learners of their first language.

These aforementioned values of verb phrases may be the domains in which intralingual or interlingual interference occur in the second language acquisition of English tenses. As temporal and aspectual values constitute the main focus of the discussion of linguistic interference, it would be necessary to investigate the extent to which confusion over such values can possibly occur as a result of the two categories of linguistic interference. The rationale behind the specific focus on linguistic interference has to do with the fundamental assumption that other factors affecting second language acquisition, such as pedagogical procedures, learning sequence, and negative affective variables, can be considered after sufficient attention has been paid to the linguistic variables contributing to the linguistic errors [6-7].

Given the rationale for focusing on the linguistic interference that may result in grammatical errors, the researcher has opted to concentrate on second language errors in situations requiring the use of the present perfect continuous, which has been considered as a "mysterious and elusive tense" (p. 25) [18]. The decision to focus on it stems from the need to investigate the aspectual and temporal values of certain verbal categories, particularly the present perfect continuous which distinctly comprises (i) both the perfective and progressive aspects, and (ii) a time frame extending from the past until the present. The discussion on verb forms that in- dicate a time frame comprising both the past and the present, and a combination of two aspects mentioned above may yield some interesting and relevant findings on how the tense can be effectively taught to speakers of other languages. Focusing on the use of the present perfect continuous, this paper seeks to obtain data that answer the following research questions:

Is intralingual interference as significant as interlingual interference in the second language learning of the present perfect continuous?

Findings for this question can be obtained through a detailed discussion on errors committed by second language learners in the area of the present perfect continuous. The following section explains how a research design aimed at eliciting related responses was employed to furnish information on the aforementioned linguistic sources of errors.

\section{RESEARCH METHOD}

\section{Data Collection Procedure}

This research was based on a grammaticality judgment test consisting of cautiously designed multiple-choice items in a design aimed at investigating learners' knowledge of the present perfect continuous. As this is not an experimental study (such as Doughty and Varela's [19] investigation into the influence of a communicative focus on the simple past and the present conditional over ESL learners' interlanguage), it was not necessary to control for (i) the participant variable (e.g., previous knowledge of grammar), and (ii) environmental variable (e.g., learning materials used in grammar-related activities) [20]. Even though prior to collecting the sample, the researcher was aware that certain variables, particularly previous training in the language and intelligence quotients, might have affected their performance on the grammaticality judgment test, this study was not aimed at investigating the correlation between their performance on a grammar test and other possible independent variables such as proficiency levels, intelligence quotients or other affective and attitudinal variables. The current study focuses on ascertaining the extent to which the learning of this verb form (which bears the temporal and aspectual features of different tenses), could be interfered with by some linguistic factors, namely their first language or the target language itself. As the cross-linguistic influence was to be investigated, the researcher opted to obtain data only from one ethnic group that spoke Malay as their mother tongue. It was a cross-sectional study of students in a national secondary school, focusing on identifying the possible effects of interlingual and intralingual factors on their grammaticality judgments.

The grammaticality judgment test was administered to 51 fourth form subjects, aged between 15 and 17 . The majority of them $(92.22 \%)$ had passed the English paper with two thirds $(66.7 \%)$ of them scoring grade B or C in the English paper of the Lower Secondary Examination. About one-tenth (9.8\%) of them had scored a distinction and $15.7 \%$ had scored grade D in the examination while only $7.8 \%$ of the subjects obtained grade $\mathrm{E}$. Most of the subjects were average students who had scored grade B or C, and as such, the results reflected the general performance of the students at the beginning of the upper secondary level. All the 51 subjects 
in the fourth form were included because we were aware that the best sample size would depend on "the degree of variability or diversity in the population" (p. 242) [21]. In this case, given that all the subjects shared the same first language and most of them, as mentioned above, were in moderate proficiency categories, it could be assumed that the degree of diversity was reasonably low and that a sample of data elicited from 51 subjects would be sufficient. More precisely, as the number of subjects included was more than 30 , it fulfilled the minimum requirement for a quantitative study [22, 23].

The reasons for selecting the students using the same first language were four-fold. First, the students in all the categories in this school, namely categories A, B, C, D and E in the English examination were more evenly distributed among Malay students than among other ethnic groups. More than two-fifths $(45.1 \%)$ of them were in categories A and B, whereas $47.1 \%$ came under categories C and D. [Most (67\%) of the Chinese students in this school, however, fell under categories A and B and only $23 \%$ of them were in categories $\mathrm{C}$ and D.] Second, it was found that all the Malay students in the fourth form spoke English as their second language, while the Indian and Chinese students in this school were not selected given that it was difficult to determine whether English was their second or third language. (Some of the Indian and Chinese students could speak English as their first, second or even third language.) Third, fourth form Malay students were selected in order to (i) focus on the comparison of one particular native language, namely the Malay language, and (ii) contrast it systematically with the target language to identify the interlingual interference in the second language acquisition of English. Fourth, a higher degree of uniformity in the preparation of the grammaticality judgment test could be achieved as the items were targeted at subjects who shared the same mother tongue.

A total of 15 multiple-choice items requiring the use of the present perfect continuous were set, with each item comprising five answer choices that (i) competed in some way with the correct answer and (ii) had linguistic features in common with those of the correct response at orthographic, morphological and/or semantic levels. With respect to the items, Table 1 was drawn up to state the rules/situations covered in the items. The rules/situations governing the use of the present perfect continuous have been described by Greenbaum and Quirk [24], Thomson and Martinet [25], Aitken [26] and Azar [27]. Even though each of the 15 items required the respondents to provide answers in a particular tense, the rubrics for the grammaticality judgment test did not indicate which tense or verb form had to be used in each case. In each item, the requirement to use a certain morphological tense is signalled to the learners via "lexical means for expressing temporality" (p. 36) [28]. This means that temporal and locative adverbials (e.g., 'for more than two hours', 'since ten o'clock', 'here', etc.) and time-related verbs (e.g., 'start', 'finish', etc.) were used to express temporality so that learners would decide on what verb forms, with their associated bound morphemes (e.g., '-en', '-ing', etc.), could be used with the free verbal morpheme (i.e., the root word such as 'play' or 'paint').

The multiple choice items were used (instead of a composition-based test) in this research because they (i) were

Table 1. Rules Governing the Use of the Present Perfect Continuous

\begin{tabular}{|c|c|c|c|}
\hline No. & Rule/Situation & Abbreviation & Example \\
\hline 1 & $\begin{array}{l}\text { For an action or event which began at a certain time in the past but has only } \\
\text { just finished. } \\
\text { (Note: A time phrase such as 'since April', 'for five months', 'never' and } \\
\text { 'always' may not be used.) }\end{array}$ & PJF & $\begin{array}{l}\text { I know the workers are going there } \\
\text { for a break. Let them have a rest, for } \\
\text { they have been working (for six } \\
\text { hours already). }\end{array}$ \\
\hline 2 & $\begin{array}{l}\text { When the speaker asks whether a particular action or event has been hap- } \\
\text { pening during a period extending from a definite time in the past until now. } \\
\text { (Note: A time phrase such as 'since April', 'for five months', 'never' and } \\
\text { 'always' may not be used.) }\end{array}$ & AWPN & $\begin{array}{l}\text { Have they been attending to the } \\
\text { same customer in/for the last two } \\
\text { hours? The other two customers are } \\
\text { complaining about the long wait. }\end{array}$ \\
\hline 3 & $\begin{array}{l}\text { (i) For an action or event which began at a certain time in the past, and it is } \\
\text { certain that it is still continuing at the time of speaking. } \\
\text { (Note: The action or event has been going on during a period extending } \\
\text { from a definite time in the past until now. A time phrase such as 'since } \\
\text { April', 'for five months', 'never' and 'always' may not be used.) }\end{array}$ & PSA & $\begin{array}{l}\text { We have been working here (for } \\
\text { more than twenty years) and will } \\
\text { certainly continue to work here until } \\
\text { we retire. }\end{array}$ \\
\hline 5 & $\begin{array}{l}\text { For an action or event which (i) has not happened for a period of time and } \\
\text { (ii) is still not happening at the time of speaking. } \\
\text { (Note: A time phrase such as 'since April', 'for five months', 'never' and } \\
\text { 'always' may not be used.) }\end{array}$ & $\mathrm{HNN}$ & $\begin{array}{l}\text { They haven't been listening to } \mathrm{Mr} \\
\text { Ooi's message. They are still talking } \\
\text { among themselves. }\end{array}$ \\
\hline 6 & $\begin{array}{l}\text { For an action or event which (i) has not happened for a period of time but } \\
\text { (ii) is happening at the time of speaking. } \\
\text { (Note: A time phrase such as 'since April', 'for five months', 'never' and } \\
\text { 'always' may not be used.) }\end{array}$ & HNA & $\begin{array}{l}\text { The computer broke down this } \\
\text { morning. I haven't been using it in } \\
\text { the last eight hours. I am glad that it } \\
\text { is working now. }\end{array}$ \\
\hline
\end{tabular}


convenient to code and analyse and could avoid off-the-wall responses, (ii) ensured that the subjects could select among alternatives that were likely to cause interference, and (iii) could measure the subjects' ability to make fine discriminations [29]. The major advantage of the multiple-choice items was that they required the subjects to discriminate among alternatives which needed a level of mastery that a free response item might not be able to detect [30]. Using a number of plausible alternatives, as Linn and Miller [31] have pointed out, made the selected choices amenable to diagnosis because the incorrect alternatives provided clues to misunderstandings or confusion that needed attention or correction.

It should be pointed out that written compositions could have been used to elicit some spontaneous responses. They were, however, not used as a method for eliciting responses in this study because observation of spontaneous performance is "generally inadequate for detailed examination of a subject's receptive and productive command of infrequent and easily avoidable forms or rules" (p. 15-16) [32]. This is based on the rationale that certain verb forms and tenses may be avoided by learners, and as a result, these verb forms might not be used spontaneously in their speech or writing. Nevertheless, it is, wrong to assume that these tenses or verb forms (that might cause interference) are not important for the purpose of analysis because the learners might have avoided them because of their ignorance of the rules governing the use of the verb forms. More precisely, pre-structured tasks such as multiple-choice items have the advantage of eliciting responses in different areas of difficulty, and this could be done to ensure that learners would not avoid using certain structures in specific situations or contexts.

In this study, the subjects' knowledge was diagnosed mainly at implicit and discriminatory levels. This means that the present research was aimed at identifying (i) whether the subjects knew the rules governing the present perfect continuous implicitly in the process of selecting a correct answer choice, and (ii) whether they were able to differentiate the instances or situations in which the rules applied. The subjects had to respond to the items given carefully, paying attention to the situation indicated by the meanings of words given in each item before deciding on the tense to be used. As the present perfect continuous could be used in different situations in which definite rules were to be adhered to, the subjects were required to understand the situations by considering the context signalled via the meanings of the words used in the sentences given.

More specifically, the test consisted of highly structured multiple choice items designed to assess the subjects' ability to recognize the correct verb forms. According to Heaton [33], objective tests have to be constructed carefully to cut down on the possibility of guessing. In this study, most of the items were of the incomplete statement type, and five alternatives given for each item were sufficient to reduce the possibility of guessing. Besides, 2-choice items have been avoided "because of the very strong effect on scores which blind guessing will have" and "if the correction-for-guessing formula is applied to all papers, a great injustice will be worked on examinees who do not blind-guess", and similarly, 3-choice items have also been avoided because "scores obtained by chance guessing would tend to run high enough to be fairly significant" (p. 129) [34].
Only five-choice items were given on the use of the present perfect continuous. As the test consisted of 15 items, it was first assumed that if a subject answered all 15 items by marking choice ' $\mathrm{D}$ ', for instance, he/she would get about one-fifth of the items (i.e., three items) correct. If his/her score was computed by taking the number of correct answers (i.e., three) and by subtracting a quarter of 12 (i.e., the number of his wrong answers), he/she would be left with a score of zero. Using this method of computation to account for the possibility of guessing, a researcher can then claim that a subject "would have gained no advantage whatever from his attempts at 'beating the game' through blind guessing" (p. 128) [34]. As Heaton [33] has pointed out, "experience shows that candidates rarely make wild guesses: most of them base their guesses on partial knowledge" (p. 26-27). In this study, each distracter (incorrect option) was made reasonably attractive and "truly distracting" (p. 49) [22] in order to appear plausible or apparently 'correct' to any subject who was uncertain of the grammatical option. Hence, the test was useful in measuring (i) the subjects' ability to recognize correct grammatical forms, and (ii) their ability to make the aforementioned discriminations in the TL.

Before decisions were made on the options to be included as distracters, informal observations were conducted among twenty percent of the subjects in a pilot study. The subjects' grammatical construction of sentences used in their conversations and written compositions was also observed during a period of three months. It was found that the degree of control and manipulation could affect (i) the kind of data which would be gathered, (ii) the analysis of results, and (iii) the researcher's ability to interpret and generalize these results. Different linguistic factors (e.g., resemblance at morphological and/or orthographic levels, degrees of comparability with the learners' first language, etc.) that might intralingually and interlingually interfere with the SLA of the present perfect continuous were taken into account.

As the subjects' errors in the pilot study and classroom observations rarely included non-verbal derivatives, it was decided that non-verbal derivatives (i.e., derivatives which are not verb forms) could be excluded from the five alternatives for an item in the main study. For example, when the subjects were expected to use the present perfect continuous for a sentence such as "He has been speaking for more than two hours already", they seldom chose a nominal derivative such as 'speech'. Wrong combinations of verb forms (e.g., 'has speak') and contextually erroneous passive forms (e.g., 'has been spoken'), however, were main options selected by a considerable number (about or more than a fifth) of the subjects in the pilot study. Hence, in the main study these non-verbal derivatives were no longer included as answer choices but were replaced with other tenses or related verb forms so that the subjects' responses could provide answers to the research question.

\section{Data Analysis Procedure}

A simple descriptive statistical procedure was used when considering the data in terms of percentages of errors, which were then compared and analyzed to identify the extent to which the errors were attributable to interlingual interference. The percentages of answer choices could then be used to ascertain (i) whether certain patterns of tense usage were 
observable, (ii) whether certain basic rules governing the use of a particular tense had been internalized, and (iii) whether the errors committed could be ascribed to cross-linguistic influence or intralingual interference. Given that the probability of selecting an answer choice was only 1/5 (i.e., $20 \%$ ), a particular erroneous answer choice selected by more than one-fifth or $20 \%$ of the subjects would be considered significant.

The criteria for determining the difference between interlingual and intralingual errors were related to the preconceived notions that (i) the subjects' L1 had considerable influence over the use of the TL, (ii) the subjects encountered some difficulties in distinguishing the rules governing the use of the present perfect continuous, and (iii) some confusion arose while the subjects were exposed to a large number of English verb forms, which resemble one another at orthographic, morphological and semantic levels. Focusing on the deviant choices, the researcher used an explanatory version of contrastive analysis (CA) to consider possible sources of errors. This entails that CA was conducted on a posteriori basis by beginning with the evidence provided by linguistic interference and by using evidence to explain the similarities and differences between language systems.

A 3-step analysis procedure was employed to study the data based on the grammaticality judgment test. In Step 1, the learners' erroneous options selected by more than a fifth of the respondents were compared with the expected correct option orthographically, morphologically, and/or semantically to identify any possible intralingual interference. In Step 2, their erroneous choices were compared with (i) corresponding correct verb forms in their first language (L1), and (ii) related but erroneous verb forms in their L1 in order to identify any possible partial similarities that might give rise to confusion. In Step 3, the errors committed in different items were compared and contrasted to identify cross-item similarities and differences that could suggest the existence of intralingual and/or interlingual interference.

\section{RESULTS AND DISCUSSION}

Using the methodology described above, the researcher focuses on analysing the grammatically deviant options and discusses the errors that are attributable to the two types of linguistic interference mentioned above. This study has found that the main distracters causing intralingual interference in the SLA of the present perfect continuous were the past perfect continuous, the present perfect, and the past continuous. Detailed explanations are provided in the following sub-sections. The data obtained for item 1 in Table 2 shows that only $35.3 \%$ of the subjects used the present perfect continuous correctly for an action which (i) began at a certain time in the past but (ii) has only just finished. Even though the present perfect can also be used in this case, nearly onefifth of the learners considered it correct to combine the perfective auxiliary 'has' with the base form (i.e., 'speak') instead of the past participle 'spoken'.

In addition, nearly a third of the respondents used the passive form of the present perfect erroneously. The subjects who combined the auxiliary 'has' with the base form 'speak' might be unaware of the morphological rule requiring the use of a past participle after a perfective auxiliary. The fact that the main verb 'speak' exists in five forms (i.e., 'speak', 'speaks', 'spoke', 'spoken' and 'speaking') may have also given rise to difficulty in using the correct form of the present perfect which can be used to replace the present perfect continuous in this case. Apart from this, the subjects who used the passive form of the present perfect erroneously did not appear to be able to recognise whether the pronoun 'he' was (i) the nominative sentence-subject (performing an action), or (ii) a sentence-object upon whom an action had been performed. The data suggest that these subjects could not differentiate between the present perfect continuous (i.e., 'has been speaking') and the passive form of the present perfect (i.e., 'has been spoken') given that both required the same auxiliary verb 'has been' in this case. These learners appeared to pay scant attention to the difference between the past participle (i.e., 'spoken') and the present participle (i.e., 'speaking') used in the present perfect continuous.

In regard to item 2 , Table 2 indicates that most $(70.6 \%)$ of the subjects did not use the interrogative form of the present perfect continuous to ask whether an action has been occurring for a period of time extending from a definite time in the past until the time of speaking. More than a quarter

Table 2. Percentages of the Subjects' Choices for Items 1 and 2 (Rules/Situations: PJF and AWPN)

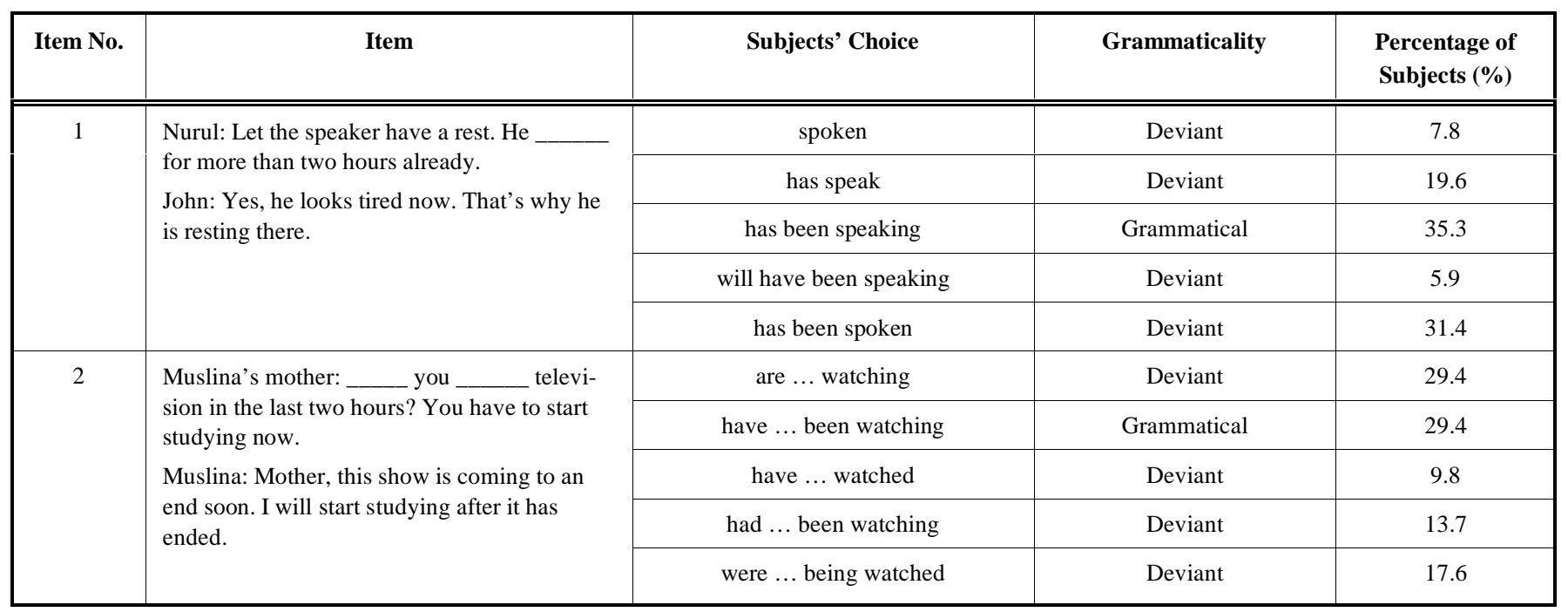


(29.4\%) of subjects used the present continuous, and an equal proportion of them chose the present perfect continuous. The results suggest that most of the respondents could not distinguish the temporal references of three tenses in particular, namely the present continuous, the past continuous, and the perfective verb forms. Those subjects who selected the present continuous did not seem to be aware that the interrogative form of the present continuous should normally be used to ask whether an action was going on at the time of speaking whereas that of the present perfect continuous had to be used to ask if an action had been happening for a period of time. The results once again suggest that the learners generally pay scant attention to the use of a temporal adverbial (e.g., 'in/for the last two hours') which is normally used to emphasise that an action has been continuing until the moment of speaking.

We shall now turn to another four items in which the present perfect continuous is needed to indicate an action which began at a certain time in the past and it is certain that the action is still continuing at the time of speaking. Table $\mathbf{3}$ indicates that more than a third of the learners used the passive form of the present perfect (i.e., 'have been polished') instead of the present perfect continuous (i.e., 'have been polishing') for the same type of action mentioned above.
More than a third $(37.3 \%)$ of the subjects used the passive form of the present perfect, and more than one-fifth $(23.5 \%)$ of them selected the present perfect (i.e., 'have polished') instead of the present perfect continuous (i.e., 'have been polishing'). The learners who used the passive form of the present perfect did not seem to know that the use of the past participle 'polished' instead of the present participle 'polishing' would mean that the verb was passive (and not active). The same perfective auxiliary verb 'have been' is used in the present perfect continuous (i.e., 'have been polishing') and the passive form of the present perfect (i.e., 'have been polished'). The use of this perfective auxiliary with the past participle would also mean that the first-person pronoun ' $I$ ' is a subject upon whom an action has been performed (i.e., recipient) instead of an action-performing sentence-subject (i.e., agent). In other words, the use of the same auxiliary (i.e., 'have been') in the passive form of the present perfect might be a cause of intralingual interference in the SLA of the present perfect continuous.

In addition, the difficulty encountered by the subjects in the use of the verbal category can be ascribed to interference from the subjects' L1. Consider the following sentences:

Table 3. Percentages of the Subjects' Choices for Items 3-6 (Rule/Situation: PSA)

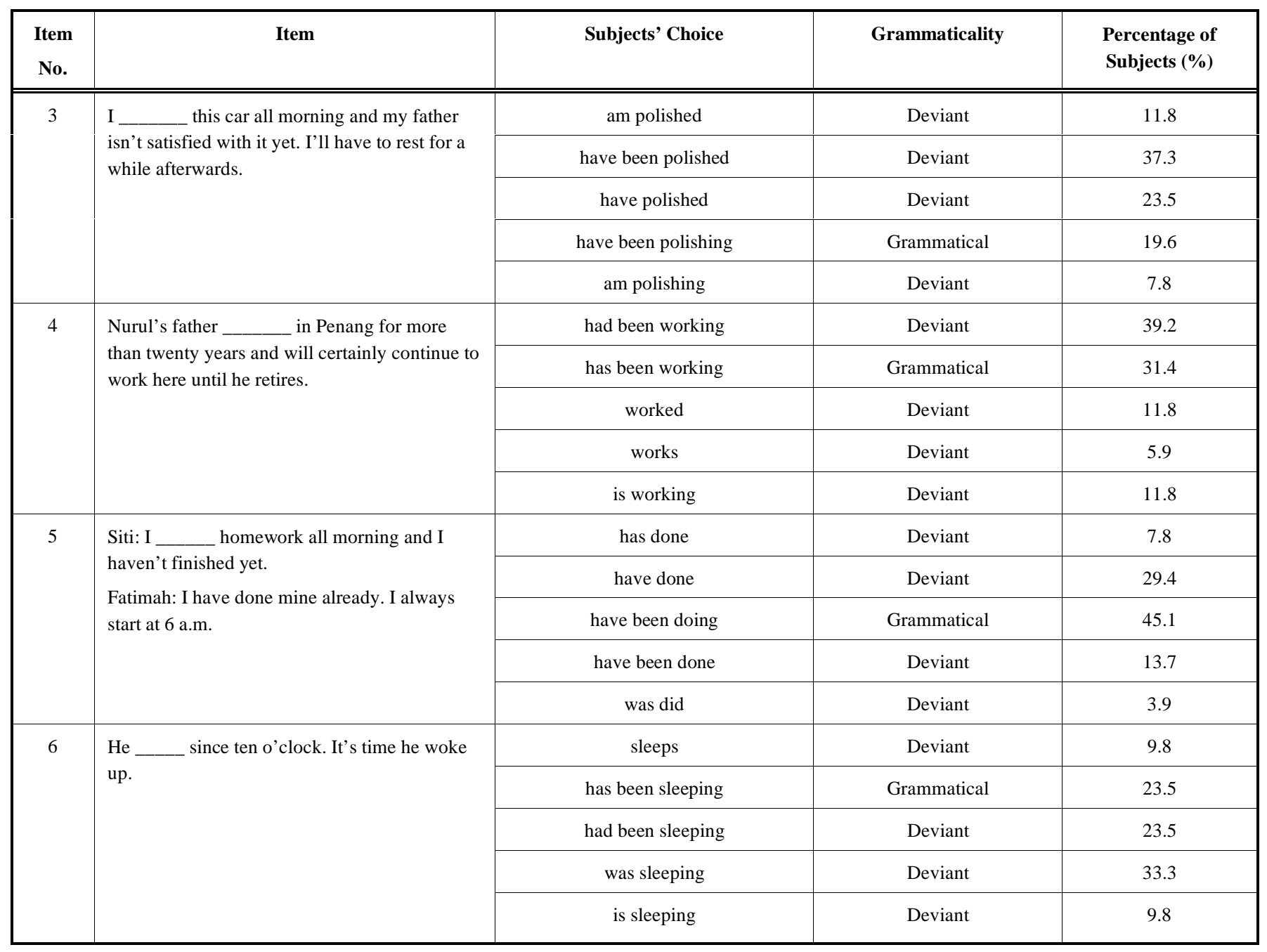


(2) I have polished this car. (English)

(3) Saya sudah menggilap kereta ini sepanjang pagi. (Malay)

(4) I have been polishing this car all morning. (English)

(5) I have polished this car all morning.* (Ungrammatical English sentence)

The perfective combination 'sudah menggilap' in sentences 1 and 3 could be translated respectively as (i) have polished' in sentence 2 for a completed action and (ii) 'have been polishing' in sentence 4 for an action which has been occurring over a period of time. The English perfective verb phrase 'have polished' as shown in sentence 5, however, is not an acceptable equivalent for the Malay perfective combination 'sudah menggilap' in sentence 3 , because only the present perfect continuous (i.e., 'have been polishing') can be used with the temporal adverbial 'all morning' to emphasize that the action has been going on for a period. Hence, the results once again support the previous finding that cross-linguistic differences in the use of perfective combinations may have made the SLA of the present perfect continuous more problematic.

In regard to item 4, Table 3 shows that nearly two-fifths of the subjects used the past perfect continuous instead of the present perfect continuous for an action which (i) began in the past and (ii) is still going on at the time of speaking. In this case, the subjects who used the past perfect continuous did not seem to know that the verb phrase, unlike the present perfect continuous, did not show any direct connection with a future action or situation. The use of the present perfect continuous in conjunction with the subsequent predicate (i.e. 'will certainly continue to work here until he retires') would indicate that the action (i.e., 'has been working') has been going on for a period of time and will continue to happen in the future (i.e., after the time of speaking).

With respect to item 5, Table $\mathbf{3}$ shows that more than a quarter $(29.4 \%)$ used the present perfect instead of the present perfect continuous for an action which has been occurring from a definite time in the past until the time of speaking. When a time phrase indicating a period of time (i.e., 'since 1995', 'for three years', etc.) is used, both the present perfect and the present perfect continuous can be used for an action which has been occurring from a definite time in the past until the present. In this case, the present perfect continuous is needed because the temporal adverbial 'all morning' is employed to emphasize that the action has been happening continuously for a period of time. The learners who used the present perfect (i.e., 'have done') might not have acquired the rule requiring the use of the present perfect continuous in the situation mentioned above, and interference from the subjects' first language may have made it more difficult for them to distinguish between the present perfect continuous and the present perfect. Consider the following sentences:

(1) Saya telah membuat kerja rumah saya. (Malay)

(2) I have done my homework. (English)

(3) Saya telah membuat kerja rumah sepanjang pagi. (Malay)

(4) I have been doing homework all morning. (English)
(5) I have done homework all morning.* (Ungammatical English sentence)

The phrase 'telah membuat' containing a perfective auxiliary 'telah' in sentences 1 and 3 may have been misconstrued as 'have done' in sentence 2 or 'have been doing' in sentence 5 respectively. However, it cannot be translated as 'have done' when it is used with the temporal adverbial 'all morning'. The present perfect continuous is acceptable when the speaker wants to emphasize that the action has been going on continuously for a period of time. It is plausible that the perfective combination 'telah membuat' (consisting of the perfective auxiliary 'telah' which is not a verb in Malay) has two different equivalents in different contexts, and crosslinguistic differences in the use of the perfective combination might have made the SLA of the present perfect continuous even more difficult.

As for item 6, Table 3 indicates that a majority $(72.5 \%)$ of the subjects did not use the present perfect continuous correctly for an action/state/event which has been occurring until the time of speaking. A third (33.3\%) of the subjects used the past continuous (e.g., 'was sleeping') even though more than one-fifth $(23.5 \%)$ of them used the present perfect continuous correctly. An equal portion of them used the past perfect continuous instead of the present perfect continuous. The subjects who used the past continuous and the past perfect continuous did not seem to realise that the adverbial 'since ten o'clock' was used by the speaker to refer to the period covered by an action that has been occurring until the time of speaking. The subjects' tendency to use the verb phrases indicating past actions might be partly due to confusion over the use of the past simple (i.e., 'woke up') for a present-unreal situation in the second sentence. Although the past simple normally refers to an action which took place at a definite time in the past, in this case it indicates a present situation which is not real. This may have caused the subjects to regard the action or event erroneously as one that occurred in the past.

We can now focus on seven items requiring the use of the present perfect continuous for an action or event which began at a certain time in the past when it is not certain whether the action is continuing at the time of speaking. Table $\mathbf{4}$ shows that a majority of the subjects used the past continuous instead of the present perfect continuous for an action which (i) has been occurring for a period of time and (ii) is still occurring at the time of speaking or has only just stopped.

The data obtained for item 7 supports the finding that the SLA of the present perfect continuous could be due to the subjects' confusion over the rule governing the use of the past continuous mentioned above. The majority $(72.5 \%)$ of the respondents used the past continuous instead of the present perfect continuous, and the results here are similar to those explained earlier on, as the learners did not seem to be aware that the past continuous (i.e., 'was making') only indicated an action occurring at a particular moment in the past instead of an action which has been occurring for a period of time.

Findings for the aforementioned item were corroborated by those for item 8 that required the use of the verbal category for the same type of action. Table $\mathbf{4}$ shows that the main 
Table 4. Percentages of the Subjects' Choices for Items 7-13 (Rule/Situation: PSN)

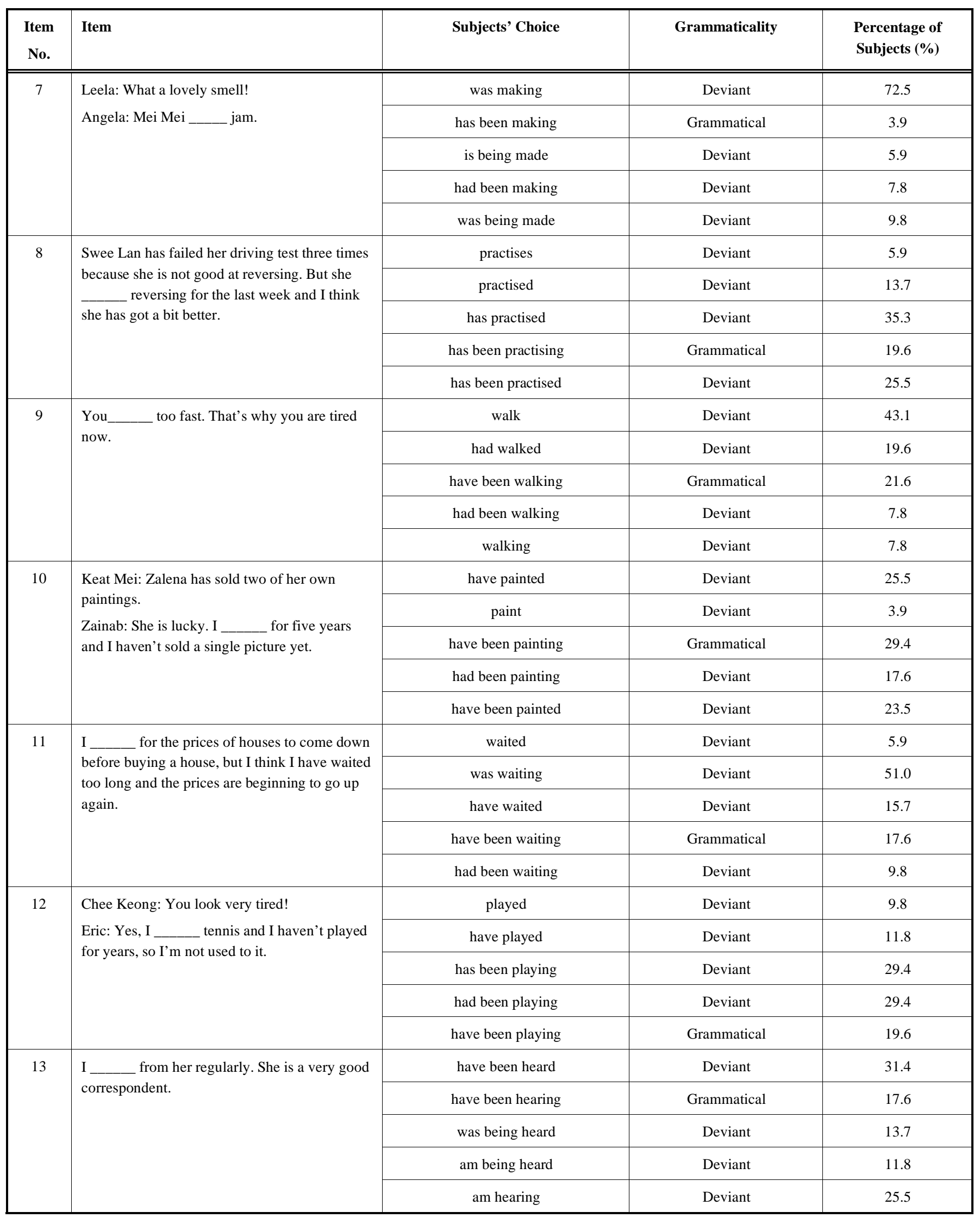


distracters that interfered with the use of the present perfect continuous were also the active and passive forms of the present perfect. Over a third $(35.3 \%)$ of the subjects used the present perfect erroneously even though in this case the present perfect continuous should be the correct form (as the time phrase 'for the last week' is included to emphasise that the action has been occurring continuously during a span of time). If the present perfect is used in this case, no emphasis is placed on the repeated nature of the action and little attention is directed to the period of time taken by the action. Consider the following sentences:

(1) She practised reversing last week.

(2) She practised reversing for a week.

(3) She has practised reversing for a week.

(4) She has been practising reversing for a week.

(5) She has been practising reversing for the last week.

(6) She has practised reversing for the last week.* (Ungrammatical English sentence)

The subjects who used the past simple and the present perfect might be confused with the different temporal references of the adverbials such as (i) 'last week' which is normally used with the past simple to refer to a definite time in the past, (ii) 'for a week' which refers to a period of time, and (iii) 'for the last week' which is used with the present perfect continuous to emphasise that an action has been happening continuously over a period of time. Furthermore, the present perfect (i.e., 'has practised') in sentence 3 and the present perfect continuous (i.e., 'has been practising') in sentences 4 and 5 could all be translated as 'telah berlatih' in the subjects' L1. Hence, the erroneous use of the present perfect with the temporal adverbial 'for the last week' (as in sentence 6) might be partly attributable to the cross-linguistic differences explained above.

With respect to item 9 , Table 4 shows that more than two-fifths $(43.1 \%)$ of the learners used the present simple (i.e., 'walk'), which is generally employed to refer to a present habitual action. These subjects who used the present simple seemed unaware that 'walk' indicated a present habitual action that has no effect at the time of speaking. Nearly one-fifth $(19.6 \%)$ of the learners selected the past perfect (i.e., 'had walked') which does not show any semantic connection with the present situation. In this case, the present perfect (i.e., 'have walked') and the present perfect continuous (i.e., 'have been walking') can be used to show the result or effect of a past action in the present. Hence, the subjects' selection of the past perfect and the present simple suggests that they might be unaware of the temporal references of the two verbal categories, which do not indicate any immediate effect at the time of speaking.

As for item 10, the data obtained also suggest that the main distracters in the use of the present perfect continuous were the active and passive forms of the present perfect. As explained above, when a temporal adverbial indicating a period of time is used, both the present perfect and the present perfect continuous can be used to refer to an action or event which began at a certain time in the past and is still going on or has only just stopped. Table 4 shows that a majority $(70.6 \%)$ of the respondents did not use the present per- fect continuous for the action mentioned above. Both the present perfect continuous and the passive form of the present perfect have the same perfective auxiliary (i.e., 'have been'). In this case, more than one-fifth $(23.5 \%)$ used the passive form of the present perfect instead of the present perfect continuous. Besides, about a quarter $(25.5 \%)$ of the subjects used the active form of the present perfect, without realising that the first-person pronoun in this case should be an action-performing agent instead of a subject upon whom an action has been performed.

In addition, the use of the active form of the present perfect in this case is also erroneous, and the interference involved may be explained with reference to the following sentences:

(1) I have been painting for five years.

(2) I have painted pictures for five years.

(3) I have painted for five years. * (Ungrammatical English sentence)

Sentences 1 and 2 are grammatically acceptable but sentence 3 is erroneous because the active form of the present perfect in this case is transitive. More precisely, even though the active form can normally be used with a time phrase (e.g., 'for five years') to indicate an action which has been occurring for a period, the passive form of the present perfect (i.e., 'have been painted') cannot be used without an object (e.g., 'pictures') in the same situation. Nonetheless, the use of the present perfect continuous without the object is grammatical as the verb can be intransitive when it is used in the progressive aspect. The subjects who used the active form of the present perfect did not seem to be aware that the transitivity of the verb in the present perfect (e.g., 'have painted') required an object (e.g., 'pictures') which was not given in this item.

In regard to item 11 , the past continuous does not show that the action has any direct connection with or any effect in the present situation, and it only shows that an action was occurring at a certain time in the past. Table $\mathbf{4}$ shows that more than half $(51.0 \%)$ of the subjects used the past continuous instead of the present perfect continuous, both of which involve the use of the present participle (i.e., 'waiting'). Even though the present perfect and the present perfect continuous are normally used for actions associated with a present situation, they are different in the absence of a temporal adverbial that indicates a period. Consider the following sentences:

(1) I have been waiting for the prices to come down.

(2) I have waited for the prices to come down since January.

(3) I have waited for the prices to come down.* (Ungrammatical English sentence)

The present perfect continuous (i.e., 'have been waiting') can be used with or without the time phrase indicating a period of time (e.g., 'since January') to refer to an action which has been occurring from a definite time in the past until the present. The present perfect, however, indicates such an action only if the speaker uses a time phrase given above. In this case, the present perfect is used without the time phrase, so it only refers to an action which has already been com- 
pleted. The present perfect in the second clause of the same sentence (see item 11 in Table 4) implies that the speaker has waited for a long time, and he is probably still waiting or has just stopped at the time of speaking. The subjects who used the present perfect instead of the present perfect continuous might be unaware of the rules governing the use of the two verb forms. The acquisition of the present perfect continuous may have been more difficult because of the cross-linguistic differences as illustrated below:

Saya sudah menunggu selama dua jam. (Malay)

I have waited for two hours. (English)

(3) I have been waiting for him for two hours. (English)

The perfective combination 'sudah menunggu' in sentence 1 might have been translated as 'have waited' in sentence 2 and 'have been waiting' in sentence 3 which are in the present perfect and the present perfect continuous respectively. The data once again support the previous finding that some subjects might be ignorant of the restrictions governing the use of the present perfect and the present perfect continuous. More specifically, their knowledge of the perfective combination 'sudah menunggu', which can have different situational equivalents in the TL, could be a cause of negative transfer.

With respect to item 12, Table 4 also shows that a majority $(80.4 \%)$ of the subjects did not use the present perfect continuous for the same type of action, but slightly different results were obtained in this case. Over a quarter (29.4\%) used the past perfect continuous (i.e., 'had been playing') instead of the present perfect continuous which could exist in two forms (i.e., 'has been playing' and 'have been playing') in this case. Only $19.6 \%$ of the respondents used the firstperson singular verb (i.e., 'have been playing') in the present perfect continuous correctly whereas more than a quarter (29.4\%) used the third-person singular verb form (i.e., 'has been playing') incorrectly. These errors can be ascribed to intralingual interference which may have occurred as a result of the subjects' confusion over the two differing forms in the present perfect continuous itself.

In brief, the subjects' tendency to use the past perfect continuous may be attributed to both intralingual and interlingual interference. Firstly, the subjects may have confused the present perfect continuous with the past perfect continuous as both of them involved the use of perfective auxiliaries (i.e., 'have been', 'has been' and 'had been') which bear some similarities phonetically and orthographically. Secondly, difficulty in the SLA of the present perfect continuous may have become more difficult because the perfective combination 'telah bermain' in the subjects' L1 could be translated into such verb forms as 'have played', 'have been playing', 'has been playing' and 'had been playing' in different contexts. The use of the past perfect continuous instead of the present perfect continuous supports the previous finding that these subjects might be unaware of the temporal references indicated by the two verb forms.

With regard to item 13, Table $\mathbf{4}$ indicates that intralingual interference is particularly prominent as the learners appear to have the tendency to use verb forms containing auxiliary verbs with which they were familiar (i.e., 'have been' and 'am') for the same action mentioned above. The tendency of nearly a third (31.4\%) of the subjects to use the passive form of the present perfect suggests that the learners encountered problems discerning between the different functions of 'have been' as a (i) passive perfective auxiliary preceding a past participle (as in 'have been heard'), and (ii) an active perfective auxiliary preceding a present participle (as in 'have been hearing'). Likewise, the learners who chose the present continuous (e.g. 'am hearing') did not appear to realise that the present continuous normally indicates an action occurring at or around the time of speaking, and it does not show a present habitual action (which is generally signalled by the present simple). In addition, nearly a third $(31.4 \%)$ of the subjects used the passive form of the present perfect (i.e., 'have been heard') instead of the present perfect continuous (i.e., 'have been hearing'). They appeared unaware that the use of the past participle 'heard' (instead of the present participle 'hearing') would make the verb phrase passive. Other than the present perfect, the past continuous could also be a main distracter in the use of the present perfect continuous for an action which has been happening for a period.

We shall now turn to the negative forms of the present perfect continuous tense. Table $\mathbf{5}$ indicates that a majority $(82.4 \%)$ of the respondents did not use the present perfect continuous correctly for an action which (i) has not been occurring for a period of time and (ii) is still not happening at the time of speaking.

In this case, the negative form of the present perfect continuous can be employed because it refers to an action which has not been happening for a period of time. The majority (76.4\%) of the subjects, however, used the auxiliaries 'don't' or 'aren't' with the wrong main verbs. For instance, the auxiliary 'don't' was combined with the present participle. The data suggest that the subjects might have been confused with the rule governing the combination of auxiliary and main verbs. Closely connected with the aforementioned item is item 15 , for which the data obtained (as shown in Table 5) show that more than half $(64.7 \%)$ of the subjects erroneously used the negative forms of the present simple and the past simple for an action which has not been happening for a period of time but is happening at the time of speaking. Nearly one-fifth $(19.6 \%)$ of the subjects used the negative form of the present simple (i.e., 'don't use') instead of the present perfect continuous. The subjects who used the past simple seemed to be confused with the meaning indicated by the temporal adverbial (i.e., 'in/for the last two hours') which indicates a period of time extending from a certain time in the past until the present. Even though the adverbial does not refer to a definite time in the past, these subjects readily preferred the past simple. Likewise, the respondents who used the present simple did not seem to realise that the present simple should be used to refer to a present habitual action instead of an action that has been occurring continuously until the present.

\section{CONCLUSION AND RECOMMENDATIONS FOR THE TEACHING OF ENGLISH AS A SECOND LAN- GUAGE}

To sum up, an error rate of $76.9 \%$ was recorded for all the items requiring the use of the present perfect continuous. The results suggest that each of the 6 rules requiring the use of the present perfect continuous had not been acquired by more than half of the learners. Overall, intralingual interfer- 
Table 5. Percentages of the Subjects' Choices for Items 14 and 15 (Rules/Situations 5 and 6: HNN and HNA)

\begin{tabular}{|c|c|c|c|c|}
\hline $\begin{array}{l}\text { Item } \\
\text { No. }\end{array}$ & Item & Subjects' Choice & Grammaticality & $\begin{array}{l}\text { Percentage of } \\
\text { Subjects }(\%)\end{array}$ \\
\hline \multirow[t]{4}{*}{14} & \multirow{4}{*}{$\begin{array}{l}\text { They____ Mr Lim's explanations. Look! } \\
\text { They are talking among themselves. }\end{array}$} & aren't listen to & Deviant & 19.6 \\
\hline & & don't listening to & Deviant & 43.1 \\
\hline & & haven't been listening to & Grammatical & 17.6 \\
\hline & & aren't listened to & Deviant & 13.7 \\
\hline \multirow[t]{3}{*}{15} & \multirow{3}{*}{$\begin{array}{l}\text { Siti: The file has already been deleted. Do } \\
\text { you know when it was deleted? } \\
\text { Fatimah: I_ } \\
\text { two hours. I have just started using it, so I } \\
\text { really don't know when the file was deleted. }\end{array}$} & didn't use & Deviant & 45.1 \\
\hline & & don't use & Deviant & 19.6 \\
\hline & & haven't been using & Grammatical & 23.5 \\
\hline
\end{tabular}

ence appears as significant as interlingual interference in the acquisition of the present perfect continuous. This conclusion is based on the observation that some similar verb forms in the target language itself were frequently confused with the present perfect continuous. There is no denying that the subjects' first language may have considerable negative influence over the subjects' choices. This is particularly significant given that the present perfect continuous and other perfective verb phrases in English may have been assumed to have the same equivalent in the learners' L1 (e.g., 'telah menunggu', 'sudah menggilap'), and hence a mismatch of equivalents partly explains why the subjects erroneously used other perfective verb phrases instead of the present perfect continuous. Nonetheless, the learners appeared to be confused with verb forms in the target language itself as well. These verb forms that became major distracters comprised (i) the passive form of the present perfect (e.g., 'has been spoken'), (ii) past simple (e.g., 'didn't use'), and (iii) other progressive verb phrases including the past perfect continuous (e.g., 'had been working'), the past continuous (e.g., 'was making'), and the present continuous (e.g., 'are watching'). These errors can be ascribed to the subjects' lack of awareness in regard to the temporal references of the verb phrases and temporal adverbials indicating actions that have been occurring for a period of time (e.g., 'all morning', 'in/for the last two hours').

Given that intralingual interference is as significant as interlingual interference and that intralingual confusion may be exacerbated by cross-linguistic differences, it is necessary to come up with a teaching strategy to minimize learning difficulties. It is recommended that a three-pronged interactive approach be employed in the teaching and learning of the present perfect continuous in particular and other verb phrases in general. It is three-pronged in that it incorporates (i) a focus on verb forms using a five-column figure (see Fig. 1), (ii) an emphasis on semantic and functional differences of verb phrases using time lines and tables specifying rules (such as Table 1), and (iii) a stress on such situational differences using exercises requiring conscious specification of the situations in which verb phrases are employed.
In the first of the three components mentioned above, learners might have to familiarize themselves with the possible forms of the present perfect continuous. (The present perfect continuous has no equivalent passive form, and hence the form that is semantically closest to it may be the passive form of the present perfect.) Firstly, they may have to be acquainted with the positive and negative forms of the present perfect continuous. The two possible active forms and two negative forms can be subsequently contrasted by using exemplary sentences with other verb forms which are likely to cause intralingual confusion. These forms may be contrasted with other verbal categories using a five-column structure as displayed in Fig. (1), which can be used to sensitize learners to the possible combinations of auxiliary verbs with main verbs. The auxiliary verbs in the top row are combined with the main verbs in the middle rows to form possible verb phrases in situations described by the temporal and temporal/frequency adverbials in the bottom row. The passive forms, in particular, are separated and placed in part 3 of column 3. This is intended to indicate that some of the passive forms, particularly those of the present/past perfect (e.g., 'has/have been used', 'had been used', etc.), are orthographically and morphologically different from the present perfect continuous (i.e., 'has/have been using').

The division of the verb phrases into different columns not only shows the possible combinations of auxiliary and main verbs but also highlights the difference between (i) the present perfect which involves the use of the past participle, and (ii) the present perfect continuous that requires the use of present participle. To be precise, intralingual interference can be minimized by precluding learners' confusion over verbal combinations and by specifying all possible verb forms that come under the same verbal category.

The second component of this three-pronged approach involves an explanation of rules using a table (such as that given in Table $\mathbf{1}$ illustrated above). This is the component in which time lines can be used while grammatical rules are being explained. Delineations of these rules and situations are helpful in that language instruction may focus not merely 


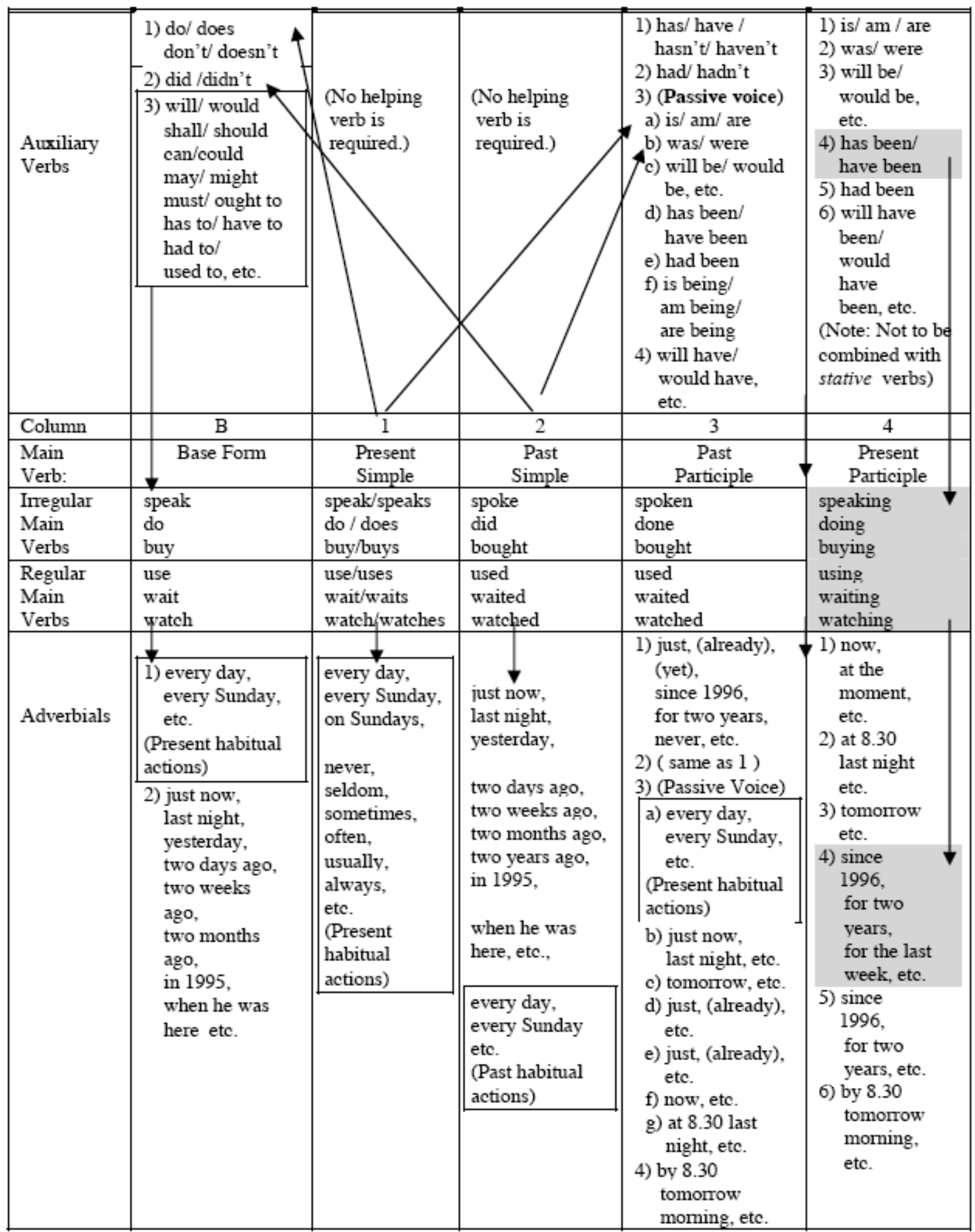

Fig. (1). Combinations of Auxiliary Verbs and Transitive Main Verbs (see also Lim [5-7]).

on form and meaning, but also on a need "to ensure that learners develop both a rich repertoire of formulaic expressions and a rule-based competence" (p. 2) [35]. Hence, in an attempt to minimize linguistic interference, time lines can be utilized to indicate temporal differences and the types of the actions while teachers explain rules. For instance, when learners fail to distinguish the present perfect continuous from the past perfect continuous, time lines may be used to indicate the differences in terms of (i) the point of inception (i.e., the point in time when the action begins/began), and (2) the point of termination of the action. [The use of time lines in explaining situations has been illustrated in textbooks and research articles on pedagogical grammars [e.g., 7, 26-27] and are not described in this paper.]

What merits attention here is that an illustration of the aforementioned rules may have to be ensued by classroom activities which extend beyond to the use of time lines and tables specifying rules. This can be ascribed to the possibility 
that a large number of rules have to be comprehended or internalized while a learner is in the process of selecting a correct verb form to use. As such, in the third component of this approach, learners who are unable to learn rules inductively may be taught to use some abbreviations representing rules and situations to (i) indicate the rationale behind their selection of a particular verb phrase, and (ii) demonstrate their competence to distinguish different temporal situations. For instance, the abbreviation 'PJF' can be employed to represent a rule/situation involving the use of the present perfect continuous for an action or event which began at a certain time in the past but has only just finished. Such conscious specification of rules/situations will raise second language learners' consciousness of the intralingual differences by drawing their attention to the adverbials and/or other contextual features of sentences which indicate the need to use a particular verb phrase. More importantly, when a learner indicates an abbreviation representing the rule that he/she thinks is appropriate, the teacher can also gather some information on the extent to which the learner comprehends the rule involved in a particular question/situation. The instructor would then be in a better position to decide on an appropriate explanation that can help the learner distinguish rules and situations in terms of both form and meaning. In brief, the three-pronged interactive approach explained above may be used to (i) provide basic training for learners who need to associate correct verb form/s with an appropriate situation, and (ii) enable an instructor to sample relevant information and opt for an explanation to minimize interference resulting from the learners' confusion with verb forms carrying different temporal and aspectual values.

\section{LIMITATIONS AND SUGGESTIONS FOR FURTHER RESEARCH}

We are aware that the use of multiple choice items (like free-response items and composition-based tests) may also have certain limitations. First, an identifiable shortcoming has to do with the difficulty in "finding a sufficient number of incorrect but plausible distracters" (p. 196) [31]. Second, in most cases both interlingual and intralingual interference appeared to have occurred concurrently, and how these two forms of interference co-occur and interact with each other may require further research using additional procedures. Hence, future research may be conducted to obtain some qualitative data based on in-depth interviews with respondents in regard to the process in which they decide on the verb form to be used in multiple choice and/or free-response items. Overall, given that the use of multiple-choice items in this study were carefully designed after related experience had been gained by the researcher via informal classroom observations of the learners' tense usage and the their responses in a pilot study, the findings obtained in the main study reported above do provide some insights into the specific areas which merit closer attention in future qualitative research that focuses on how second language learners make tense choices.

\section{VITAE}

Dr. Jason Miin-Hwa Lim is an Associate Professor of English at the Malaysian University of Sabah. He has taught Syntax and the Structure of English, Discourse Analysis,
English Phonology, and English for Research Purposes. He is currently supervising Ph.D. and Master's students in Applied Linguistics and English Language Studies. His recent international refereed publications include papers on ELT and ESP in System (UK), Asian Journal of English Language Teaching (Hong Kong), English for Specific Purposes (USA), Asian EFL Journal (British Virgin Islands), Grammar in the Language Classroom (Singapore), Researching Content and Language Integration in Higher Education (Holland), and The Open Applied Linguistics Journal (Bentham Science Publishers). He was also a Fulbright Research Scholar at the University of Michigan in Ann Arbor in 2009 and 2010 .

\section{ACKNOWLEDGMENTS}

I would like to thank the Fulbright Organization of the United States of America for a research grant that has made it possible for me to obtain related references at the University of Michigan in Ann Arbor. I am also indebted to several anonymous reviewers for their insightful comments on the previous version of this paper.

\section{REFERENCES}

[1] Gass S, Selinker L. Second language acquisition: an introductory course. London: Lawrence Erlbaum 2001.

[2] Ellis R. Item versus system learning: Explaining free variation. Appl Ling 1999; 20(4): 460-480.

[3] Selinker L. Rediscovering interlanguage. London: Longman Group Ltd 1992.

[4] Matthews PH. The concise oxford dictionary of linguistics. Oxford: Oxford University Press 1997.

[5] Lim JMH. Target language interference in the acquisition of the past simple tense. In: James JE, Ed. Grammar in the language classroom: changing approaches and practices. Singapore: SEAMEO Regional Language Centre 2003a; pp. 254-293.

[6] Lim JMH. Interference in the second language acquisition of the present simple tense. Asian J Engl Lang Teach (Hong Kong) 2003b; 13: 1-28.

[7] Lim JMH. Associating interference with strategy instruction: an investigation into the learning of the present continuous. Asian EFL $\mathrm{J}$ (British Virgin Islands) 2006; 8(2): 55-75.

[8] Richards JC. A noncontrastive approach to error analysis. Eng Lang Teach J 1971; 25: 204-219.

[9] Cowan JR. Toward a psychological theory of interference in second language learning. TESL Stud 1977; 2: 51-63.

[10] Schachter J, Celce-Murcia M. Some reservations concerning error analysis. TESOL Q 1971; 11: 441-451.

[11] Duskova L. On sources of errors in foreign language learning. In: Robinett BW, Schachter J, Eds. Second language learning: contrastive analysis, error analysis and related aspects. Ann Arbor: The University of Michigan Press 1986; pp. 215-255.

[12] Chen CY, Huang HY. L2 Acquisition of subject-prominence by EFL students in Taiwan. English Teach Learn 2003; 27(4): 99-122.

[13] Collins L. The role of L1 influence and lexical aspect in the acquisition of temporal morphology. Lang Learn 2002; 52(1): 43-94.

[14] Jarvis S. Methodological rigor in the study of transfer: identifying L1 Influence in the interlanguage lexicon. Lang Learn 2000; 50(2): 245-309.

[15] Olsen S. Errors and compensatory strategies: a study of grammar and vocabulary in texts written by Norwegian learners of English. System 1999; 27(2): 191-205.

[16] Chen LL. The effect of the use of L1 in a multimedia tutorial on grammar learning: An error analysis of Taiwanese beginning EFL learners' English Essays. Asian EFL J 2006; 8(2): 76-110.

[17] Lin SF. A case of study of English writing competence of students at the Mei Ho Institute of Technology. J Mei Ho Inst Technol 2002; 20: 180-206.

[18] Parrott M. Grammar fallacies of our age: the present perfect continuous for events which continue into the present. Mod Engl Teacher 2001; 10(4): 25-27. 
[19] Doughty C, Varela E. Communicative focus on form. In: Doughty C, Williams J, Eds. Focus on Form in Second Language Acquisition. Cambridge: Cambridge University Press 1998; pp. 114-138.

[20] Gay LR, Mills GE, Airasian P. Educational research: Competencies for analysis and applications, $9^{\text {th }}$ ed. London: Pearson Education International 2009.

[21] Neuman WL. Social research methods: qualitative and quantitative approaches, $6^{\text {th }}$ ed. New York: Pearson Education 2006.

[22] Brown JD. Testing in language programs: a comprehensive guide to English language assessment. New York: McGraw-Hill 2005.

[23] Carver RH, Nash JG. Doing data analysis with SPSS version 16. Belmont, CA: Brooks/Cole, Cengage Learning 2009.

[24] Greenbaum S, Quirk R. A student's grammar of the english language. Harlow, Essex: Pearson Education Limited 1990.

[25] Thomson AJ, Martinet, AV. A practical English grammar, $4^{\text {th }}$ ed. Oxford: Oxford University Press 1986.

[26] Aitken R. Teaching tenses. Surrey: Thomas Nelson \& Sons Limited 1992.

[27] Azar BS. Understanding and using English grammar. New York: Pearson Education 2000.
[28] Bardivi-Harlig K. Tense and aspect in second language acquisition: Form, meaning, and use. Oxford: Blackwell Publishers 2000.

[29] Carey LM. Measuring and evaluating school learning. $3^{\text {rd }}$ ed. Boston: Allyn and Bacon 2000.

[30] Hopkins KD, Stanley JC, Hopkins, BR. Educational and psychological measurement and Evaluation, $7^{\text {th }}$ ed. Needham Height, Massachusetts: Allyn and Bacon 1990.

[31] Linn RL, Miller MD. Measurement and assessment in teaching, $9^{\text {th }}$ ed. Upper Saddle River, NJ: Pearson Education 2005.

[32] Shih MC. Methods for diagnosing the second language learner's knowledge of target language rules. PhD thesis submitted to Yale University. Ann Arbor: University Microfilms International 1979.

[33] Heaton JB. Writing English tests, $2^{\text {nd }}$ ed. New York: Longman Group Limited 1988.

[34] Harris DP. Testing English as a second language. New York: McGraw-Hill Book Company 1969.

[35] Ellis R. Principles of instructed language learning. Asian EFL J 2005; 7(3): 9-24. 